\title{
Associativismo e representação política feminina no Brasil
}

Nas últimas décadas, a reduzida presença feminina nas instâncias de representação política adquiriu um lugar de destaque na agenda de debates sobre as democracias contemporâneas. $\mathrm{O}$ consenso de que a sub-representação política desse grupo é um alicerce de injustiças foi reforçado por trabalhos que demonstraram que a presença de mulheres nas instituições políticas impacta a formação das agendas temáticas decisórias. Pesquisas sobre o Brasil (Pinheiro, 2006), em outros países da América Latina (Schwindt-Bayer, 2010) e nos Estados Unidos (Carroll e Fox, 2006), mostraram, por exemplo, que a atuação política institucional feminina, em comparação com a masculina, tende de forma geral a priorizar determinados grupos - como crianças, idosos, portadores de necessidades especiais e as próprias mulheres -, e a introduzir preocupações de gênero em diferentes áreas de políticas públicas.

Assim, a ausência ou reduzida presença de mulheres na política institucional não expressa meramente uma injustiça quantitativa fartamente evidenciada pelas estatísticas que mostram o desequilíbrio numérico existente na grande maioria das democracias ocidentais entre, de um lado, o peso

Professora do Programa de Pós-graduação em Ciências Sociais da Universidade Estadual de Maringá (Maringá, PR, Brasil). E-mail: carlaalm@uol.com.br

** Professora do Departamento de Sociologia e Ciência Política na Universidade Federal de Santa Catarina (Florianópolis, SC, Brasil) e bolsista de produtividade do CNPq. E-mail: ligia@cfh.ufsc.br

**** Professor do Departamento de Ciências Sociais da Universidade Estadual de Maringá (Maringá, PR, Brasil).E-mail: ednaldorip@uol.com.br 
feminino na composição das populações nacionais e no seu eleitorado e, de outro, a presença delas no sistema político. Esta sub-representação configura também uma injustiça na medida em que indica a primazia nas arenas decisórias de determinados temas, grupos e interesses em detrimento de outros. Esse fenômeno evidencia as interdependências entre a representação descritiva, geralmente associada a perguntas sobre "quem representa?", e a representação substantiva, que nos leva a perguntas sobre "o quê representa", tornando particularmente importante o diagnóstico das barreiras que as mulheres enfrentam para entrar no sistema político, como o próprio diagnóstico do perfil daquelas que obtém sucesso em tal empreitada.

Os objetivos definidos para este trabalho o inserem nessa segunda vertente de preocupação. Com base em dados biográficos coletados no portal da Câmara dos Deputados, analisamos aqui o perfil associativo e participativo de deputadas federais brasileiras eleitas nas três últimas legislaturas, a $52^{\mathrm{a}}$, 53 a $\mathrm{e}$ 54a , respectivas aos mandatos de 2003-2007, 2007-2011 e 2011-2015. ${ }^{1}$ Os dados permitem conclusões sobre o peso das diferentes modalidades associativas nas carreiras das deputadas e sobre suas relações com o pertencimento partidário.

A fim de analisar esses dados, o trabalho dialoga com três campos temáticos de pesquisa: gênero, associativismo e representação política. Em outro estudo (Lüchmann e Almeida, 2010), discutimos a relação entre associações, gênero e representação pelo registro da atuação feminina em espaços de representação institucional alternativos, como os Conselhos Gestores de Políticas Públicas. Aqui, pretendemos ampliar o foco e dialogar com a literatura que tem apontado para as relações positivas entre a participação política das mulheres nos espaços "não convencionais" - em movimentos sociais e junto ao associativismo de maneira geral - e a representação política eleitoral (Pinheiro, 2006; Araújo, 2010).

Dada a natureza quantitativa, bem como a insuficiência de dados, diferente de atestar relações de causalidade entre participação associativa e representação política ${ }^{2}$, o trabalho pretende problematizar as bases associativas do

Na ausência de informações sobre associativismo no perfil biográfico disponível no portal da Câmara dos Deputados (http://www2.camara.gov.br/deputados/pesquisa), vários sites pessoais de deputadas foram consultados.

O que implicaria em adotarmos outras metodologias como aplicação de entrevistas e cruzamento de diferentes variáveis consideradas centrais nos processos de recrutamento eleitoral, a exemplo da organização partidária, do perfil sócio-econômico, da trajetória política familiar, da inserção em redes políticas, econômicas etc. 
recrutamento político de um grupo cuja sub-representação constitui um dos sérios problemas enfrentados pela maioria das democracias contemporâneas.

Para cumprir seus objetivos, o texto está dividido em duas partes: na primeira, apresentamos contribuições bibliográficas que tratam das relações entre associativismo e democracia enquanto moldura teórica que fornece bases analíticas para se pensar questões mais diretamente focadas nas relações entre participação, representação política e gênero; na segunda parte, apresentamos os dados referentes à atuação associativa e participava das deputadas brasileiras, de modo a sugerir alguns padrões relacionados ao capital associativo de parlamentares femininas no país.

\section{Associativismo e democracia: participação e representação política feminina}

As associações formam a base dos principais conceitos que sustentam perspectivas alternativas ou renovadoras da democracia, seja por desempenharem funções de cooperação com os governos, por ampliarem espaços de representação política e/ou contestarem padrões culturais e institucionais. Os conceitos de capital social, sociedade civil e de movimentos sociais podem ser apontados como referências centrais nestas diferentes concepções teóricas que relacionam o associativismo com os processos de ampliação e de aprofundamento da democracia.

Podemos destacar, na literatura, as principais contribuições das associações ao processo democrático. Em primeiro lugar, as associações são analisadas pelos impactos positivos no sentido da promoção de indivíduos "mais cidadãos", aumentando seu senso de eficácia política e desenvolvendo virtudes cívicas, servindo como escolas de cidadania (Fung, 2003; Pateman, 1992; Putnam, 1996; Warren, 2001).

Em segundo lugar, as associações denunciam injustiças e tencionam as relações, os padrões e os poderes tradicionais. Os movimentos sociais são aqui os sujeitos centrais. As associações também são valorizadas por desempenharem um papel central na participação em estruturas estatais que foram desenhadas tendo em vista a incorporação da população em processos de discussão e de definição de políticas públicas e governamentais, como são os casos dos conselhos gestores e orçamentos participativos no Brasil. Além disso, as associações contribuem para a qualidade da representação política ao apresentarem novas demandas, transmitirem propostas mais bem infor- 
madas e detalhadas, problematizarem interesses e políticas, e organizarem debates e interesses que transcendem limites territoriais. As associações oferecem canais adicionais aos mecanismos convencionais (voto, lobbies, contatos diretos com políticos) (Fung, 2003; Warren, 2001) para indivíduos e grupos apresentarem suas demandas no campo político-institucional.

Três observações merecem destaque nesse debate sobre as relações entre as associações e a democracia. Em primeiro lugar, os limites dos recortes teóricos, como teorias da sociedade civil e dos movimentos sociais, por exemplo, que excluem uma variedade de práticas associativas, seja por serem mais estruturadas e hierarquizadas, como sindicatos ou associações profissionais, por exemplo; seja por sua configuração, digamos, menos pública, a exemplo de grupos de idosos e clubes sociais. Em segundo lugar, o alto grau de generalização acerca dos impactos democráticos das associações, sem maiores cuidados no que se refere à necessidade de se especificar, no interior desse campo complexo e plural, os diferentes tipos de associações e seus diferentes, e muitas vezes contraditórios, efeitos democráticos. Alguns autores (Paxton, 2002; Stolle e Rochon, 1998; Baggetta, 2009; Robteutscher, 2005; Fung, 2003; Chambers e Kopstein, 2006; Dagnino, Olvera e Panfichi, 2006) vêm procurando desagregar os diferentes tipos de associações, com destaque para o trabalho de Warren (2001). Entra aqui o reconhecimento de que muitas associações não são boas para a democracia, como determinados grupos privados, grupos racistas, de ódio, e muitos grupos de interesses poderosos que fazem jus às suspeitas de facciosismo levantadas por Madison e Rousseau em suas preocupações com o ideal do bem comum (Warren, 2001, p. 10). Em que pese este reconhecimento, e embora a grande dificuldade de construir um quadro teórico diante da diversidade do mundo associativo, parece possível, de acordo com Warren, construir uma teoria das associações no interior da teoria democrática que permita não apenas ampliar o campo do associativismo, como distinguir as diferentes funções democráticas das associações, desenhando um quadro plural denominado metaforicamente de uma "ecologia democrática das associações" (Warren, 2001, p.12).

Finalmente, os limites das análises que tendem a reproduzir um viés que separa a prática da representação política (levada a cabo pelos representantes dos partidos políticos escolhidos em sufrágio universal) da participação (capitaneada pelas associações nos espaços sociais e institucionais), sem atentar para as relações entre participação social e representação eleitoral. 
Assim, além de promover práticas de representação política alternativa, associações podem ser cruciais para a conformação do quadro da representação política eleitoral.

Procurando contemplar a variedade de práticas associativas - suas diferenças no que diz respeito aos recursos, às formas de organização e aos objetivos, entre outros aspectos - , bem como o caráter relacional das práticas participativas e representativas, adotamos aqui uma perspectiva analítica que apresenta diferenças importantes que balizam, de forma substantiva, graus variados de possibilidades e de limites para o estabelecimento de relações positivas entre as práticas associativas e o desenvolvimento de indivíduos, de práticas e/ou de instituições democráticas. Resgatando a literatura sobre o associativismo, Warren (2001) sistematiza, num plano mais genérico, três conjuntos de benefícios - diretos ou indiretos - democráticos decorrentes das práticas associativas, quais sejam, efeitos no desenvolvimento individual - como sentimento de eficácia política, provisão de informações mais qualificadas, de habilidades políticas, de pertencimento coletivo, de socialização, de desenvolvimento de virtudes cívicas, de formação de lideranças políticas; efeitos na esfera pública, criando espaços de debates, expondo relações de desigualdades e de injustiças sociais e representando diferenças; e efeitos institucionais, seja criando instituições participativas, subsidiando políticas públicas e/ou ampliando as bases de representação política. ${ }^{3}$

Além disso, e fazendo coro à literatura que avalia positivamente o papel do associativismo para a democracia, as associações, elementos centrais do conceito de capital social, adensam as redes e os vínculos sociais, o que traz benefícios tanto privados, ajudando, por exemplo, nas carreiras profissionais ou na formação de lideranças políticas e sociais (Caiazza e Putnam, 2005), quanto benefícios públicos, como a cooperação, a confiança, a reciprocidade, sustentáculos importantes de uma sociedade democrática (Putnam, 1995; 1996).

A ideia de ecologia diz respeito ao reconhecimento de que diferentes tipos de associações podem provocar diferentes efeitos democráticos, evitando esperar que a mesma associação combine todos as virtudes elencadas, sendo ao mesmo tempo representativas, cultivadoras de virtudes cívicas, formadoras de lideranças, etc. Ao contrário, associações que desempenham um tipo de função podem, por várias razões, ser incapazes de exercer outras. Importante

Uma exposição mais detalhada desta proposta teórica desenvolvida por Warren pode ser encontrada em Lüchmann (2011). 
registrar que não se trata de defender uma visão fixa e essencialista das funções que podem ser desempenhadas pelas distintas modalidades de associação na democracia, mas de considerar as diferenças relativas a elas para um melhor entendimento da heterogeneidade constitutiva do fenômeno associativo. Em determinadas condições, algumas são importantes para o exercício da governança, outras para desenvolver habilidades cívicas ou resitência, etc. Um dos problemas de generalizar diz respeito ao fato de se apontar impactos democráticos onde eles não existem (Warren, 2001, p.141). Assim, sindicatos, associações profissionais, associações religiosas, organizações assistenciais, grupos comunitários, movimentos sociais apresentam diferentes potenciais, ou benefícios democráticos, a depender de seus objetivos, do contexto político vigente, da sua organização ${ }^{4}$, estratégias e recursos. Com efeito, grupos mais periféricos, como grupos religiosos e associações comunitárias podem ser boas para o desenvolvimento de solidariedades e de lideranças locais, por exemplo, mas pouco eficazes na capacidade de inserção em redes sociais e político-institucionais. De outra forma, sindicatos e associações profissionais operam sob estruturas mais complexas e com mais recursos, alcançando grandes categorias populacionais. Estimulam o desenvolvimento de habilidades políticas com avaliação de estratégias, enfrentamentos de conflitos e articulação e negociações com diferentes atores político-institucionais. Além disso, operam em redes mais densas de articulação que se estruturam em diferentes níveis da federação. Da mesma forma, os movimentos sociais, enquanto redes de interação de grupos, indivíduos e organizações que compartilham identidades (Melucci, 2001; Diani e Bison, 2010; Scherer-Warren, 2006) apresentam forte capacidade de manifestação de conflitos na esfera pública e de representação dos interesses e demandas dos grupos sociais mais vulneráveis, atuando em diferentes espaços políticos e sociais.

Essas discussões têm importantes consequências para o tema abordado nesse trabalho. Primeiro, é importante registrar que, de forma geral,

O fato de ser voluntária ou não, por exemplo, tem importantes desdobramentos. Nas associações voluntárias, os conflitos internos tendem a ser mais limitados, seja em função da facilidade da saída como meio menos custoso em situações de conflito, seja pelo forte caráter identitário dado pelos processos de autoseleção que tendem a favorecer um grupo mais homogêneo. Nestes casos, os conflitos internos são mais raros, já que potencializam a ameaça da solidariedade e da missão da associação (Warren, 2001, p 98). Nas associações não voluntárias, caracterizadas pela dificuldade ou maior custo de saída, como são os casos, por exemplo, de sindicatos ou associações profissionais, os conflitos internos se colocam de forma mais clara. 
elas parecem sustentar o que pesquisas empíricas sobre carreiras políticas têm afirmado: o envolvimento em práticas associativas potencializa, dependendo do contexto político, as chances de vitória eleitoral. Coradini (2007) afirma, por exemplo, que a intensificação da concorrência eleitoral no Brasil em virtude da redemocratização tornou o capital associativo um importante recurso político. Sua pesquisa mostra que, entre 1994 e 2003, o crescimento dos vínculos associativos de deputados eleitos foi constante. Por outro lado, a pesquisa de Araújo (2010) mostrou que, em sistemas eleitorais nos quais vigoram Listas Fechadas, as negociações intrapartidárias têm um peso maior para os processos que envolvem o recrutamento político. No Brasil, onde não vigora esse dispositivo, o capital político advindo de recursos financeiros ou redes de apoio, com destaque para as práticas associativas, torna-se fundamental.

No que se refere ao grupo que nos interessa mais de perto, considerando as oportunidades de participação abertas pelo processo de redemocratização brasileira, a pesquisa de Pinheiro (2006) indicou que vem aumentando o número de deputadas brasileiras oriundas de movimentos sociais, ainda que o capital político familiar continue propiciando uma importante porta de entrada para elas na política institucional. Isso indica o crescimento de mulheres que chegam ao sistema político em função de uma liderança construída no interior de movimentos e associações, com importantes impactos, como mostra a autora, sobre sua atuação parlamentar.

Em segundo lugar, a bibliografia que trata das relações entre associativismo e democracia sugere que faz diferença o tipo de participação associativa no que diz respeito aos seus impactos na capacidade de se constituir em porta de entrada na política institucional, fenômeno que também vem sendo confirmado por algumas pesquisas. Estudos com recorte por gênero revelam diferenças significativas na atuação associativa das mulheres quando comparadas aos homens. Caiazza e Putnam (2005), por exemplo, ao resgatarem os estudos sobre a participação feminina, apontam algumas especificidades quanto aos temas e aos vínculos associativos: as mulheres gastam mais energia e tempo atuando em questões como educação e estão mais envolvidas em grupos focados em ajudar os mais pobres, idosos e sem teto, por exemplo. Conhecem melhor os seus vizinhos e são mais propensas a se engajarem em atividades religiosas. 
Voltado para dados sobre a realidade brasileira, o estudo de Sacchet (2009) também corrobora essas diferenças por gênero no perfil associativo da população. Enquanto os homens apresentam maior vinculação com associações relacionadas com a esfera pública, referentes ao mundo da política e do trabalho, por exemplo, as mulheres estão mais vinculadas em associações que lidam com assuntos relacionados aos cuidados, à religiosidade, à família e à comunidade. De acordo com a autora, em que pese os benefícios na constituição de laços pessoais, de solidariedade comunitária, de potencial politização de temas e demandas pela gramática dos direitos, essa participação periférica não gera capital político suficiente para alimentar um retorno político-eleitoral. Os homens, por seu turno, "associam-se mais em grupos ligados à esfera pública, os quais auxiliam na formação de redes interpessoais mais heterogêneas, que criam incentivos políticos e geram recursos político e financeiro" (Sacchet, 2009, p. 324).

Nesse registro podemos sugerir, pensando nos possíveis impactos entre a participação em associações e a inclusão política das mulheres por meio da representação eleitoral, que a fecundidade dessas relações depende do tipo de associação e de suas relações - tanto internas, quanto externas, seja com partidos políticos, com outras associações, agências governamentais, entre outras. A riqueza do campo associativo traduz a diversidade e a complexidade das relações, a exemplo daquelas estabelecidas entre atores sociais (entre si) e com os atores político-institucionais, materializadas, nos casos brasileiros, por sindicatos, associações estudantis, movimentos sociais, partidos políticos e agentes governamentais, para citarmos apenas alguns exemplos. ${ }^{5}$ Assim, estudos que articulam os problemas da participação feminina nas associações e movimentos sociais com os da representação feminina no sistema institucional oferecem caminho particularmente profícuo para uma compreensão mais ampla das barreiras e das potencialidades existentes para a ampliação da presença das mulheres na vida pública.

Vários estudos vêm analisando as diferentes relações e, em alguns casos, transposições entre associações, movimentos sociais e instituições e atores político-institucionais, por exemplo: Goldstone (2003), Dagnino, Olvera e Panfichi (2006) e Abers e Bülow (2011). 


\section{Características do perfil associativo e participativo das deputadas brasileiras}

É fundamental esclarecer que consideramos para essa investigação o total de deputadas listadas pelo portal do Congresso Nacional na busca realizada para cada uma das legislaturas abordadas. Isto significa que nosso banco de dados incluiu, além das deputadas em exercício, as licenciadas, as suplentes, as que renunciaram ou perderam os seus mandatos. A soma dos casos considerados extrapola, portanto, a composição dos 513 deputados federais. Essa opção se deve ao nosso interesse de contemplar o conjunto mais amplo daquelas mulheres que obtiveram êxito na competição eleitoral para o legislativo brasileiro, independentemente do seu enquadramento institucional no momento da coleta de dados, até porque, esse enquadramento pode variar ao longo da legislatura (a suplente pode entrar em exercício, como a que está em exercício pode se licenciar, renunciar ou perder seu mandato). Para uma visão geral do universo considerado, com a inclusão dos casos masculinos pelo mesmo procedimento, segue a Tabela 1 .

Tabela 1 - Distribuição dos gêneros pelas legislaturas

\begin{tabular}{c|c|c|c}
\hline \multirow{2}{*}{} & \multicolumn{3}{|c}{ legislaturas } \\
\cline { 2 - 4 } & $\mathbf{2 0 0 3 - 2 0 0 7}$ & $\mathbf{2 0 0 7 - 2 0 1 1}$ & $\mathbf{2 0 1 1 - 2 0 1 5}$ \\
\hline feminino & 52 & 52 & 53 \\
\hline masculino & 577 & 584 & 531 \\
\hline
\end{tabular}

Fonte: Elaborado com base em informaçōes do portal do Congresso Nacional: http://www2.camara.gov.br/deputados/ pesquisa, acessado em 29/01/2012.

Se fossemos considerar apenas os parlamentares em exercício, os números seriam os seguintes: na legislatura de 2003-2007, teríamos 42 mulheres e 471 homens; na de 2007-2011, teríamos 45 mulheres e 468 homens; na de 2011-2015, teríamos 46 mulheres e 467 homens. Em razão da presença de algumas deputadas reeleitas, nas tabelas que apresentam as distribuições de frequência e os testes de associação optamos por dispor os dados por legislatura inicialmente e, em uma última coluna, o agregado. Essa última informação, portanto, comporta repetições de dados nos casos de reeleição. 


\section{Associativismo e suas modalidades}

A Tabela 2 apresenta os índices de associativismo encontrados para as deputadas em cada uma das três legislaturas consideradas:

Tabela 2 - Índice de associativismo entre deputadas federais, por legislatura

\begin{tabular}{c|c|c|c|c|c|c|c|c}
\hline \multirow{2}{*}{ IA } & \multicolumn{9}{|c}{ legislaturas } \\
\cline { 2 - 9 } & \multicolumn{2}{|c|}{$2003-2007$} & \multicolumn{2}{c}{$2007-2011$} & \multicolumn{2}{c}{$2011-2015$} & \multicolumn{2}{c}{ agregado } \\
\cline { 2 - 9 } & $\mathrm{N}$ & $\%$ & $\mathrm{~N}$ & $\%$ & $\mathrm{~N}$ & $\%$ & $\mathrm{~N}$ & $\%$ \\
\hline 0 & 16 & 30.8 & 18 & 34.6 & 22 & 41.5 & 56 & 35,7 \\
\hline 1 & 19 & 36.5 & 18 & 34.6 & 18 & 34.0 & 55 & 35 \\
\hline 2 & 10 & 19.2 & 11 & 21.2 & 9 & 17.0 & 30 & 19,1 \\
\hline 3 & 5 & 9.6 & 5 & 9.6 & 3 & 5.7 & 13 & 8,3 \\
\hline 4 & 2 & 3.8 & & & 1 & 1.9 & 3 & 1,9 \\
\hline total & 52 & 100 & 52 & 100 & 53 & 100 & 157 & 100 \\
\hline
\end{tabular}

Fonte: Pesquisa Associativismo e representação política feminina.

Se a pesquisa de Pinheiro (2006) para as legislaturas compreendidas entre o período de 1987 a 2002 apontou que a participação em movimentos sociais constituía um capital político central para 30,3\% das deputadas eleitas, conforme a nossa Tabela 2, a consideração mais ampla dos vínculos associativos existentes entre elas para o período entre 2003 e 2011 indicou um aumento significativo da presença da "participação" nas suas carreiras políticas. Nas três legislaturas consideradas, mais da metade das deputadas apresenta pelo menos 1 (um) tipo de vínculo associativo. Esses dados nos permitem afirmar que, embora seu peso possa variar como recurso político, assumindo maior ou menor centralidade nas carreiras das deputadas dependendo do caso considerado, a participação em associações constitui um importante elemento da trajetória política das mulheres que obtêm sucesso na competição eleitoral para a Câmara dos Deputados. Essa constatação nos leva a considerar a hipótese de que, mesmo nos casos em que a participação associativa possa ser um elemento secundário nas trajetórias políticas, os vínculos e as relações oportunizadas por essa participação podem potencializar outros tipos de capitais políticos e fazer a diferença nos processos de competição eleitoral para o universo em questão.

A Tabela 3 apresenta a distribuição da frequência das modalidades de associativismo encontradas entre as deputadas nas legislaturas consideradas: 
Tabela 3 - Modalidades de associativismo entre deputadas federais, por legislatura (\%)

\begin{tabular}{c|c|c|c|c}
\hline \multirow{2}{*}{} & \multicolumn{4}{|c}{ legislaturas } \\
\cline { 2 - 5 } & $2003-2007$ & $2007-2011$ & $2011-2015$ & agregado \\
\hline religiosa & 1,9 & 3,8 & 9,4 & 5,1 \\
\hline comunitária & 9,6 & 11,5 & 9,4 & 10,2 \\
\hline estudantil & 13,5 & 15,4 & 9,4 & 12,7 \\
\hline sindicatos & 36,5 & 32,7 & 22,6 & 30,6 \\
\hline profissional & 25 & 9,6 & 5,7 & 13,4 \\
\hline assistencial & 5,8 & 5,8 & 3,8 & 5,1 \\
\hline organização de mulheres & 13,5 & 13,5 & 17 & 14,6 \\
\hline direitos humanos & 11,5 & 9,6 & 9,4 & 10,2 \\
\hline defesa de grupos & 0 & 3,8 & 5,7 & 3,2 \\
\hline fiscalização de governo & 1,9 & 0 & 0 & 0,6 \\
\hline $\mathrm{n}$ & 52 & 52 & 53 & 157 \\
\hline
\end{tabular}

Fonte: Pesquisa Associativismo e representação política feminina.

Considerando estudos que mostram que a atuação das deputadas, mais do que a dos deputados, é marcada pela defesa de grupos específicos como crianças, idosos e portadores de necessidades especiais, vale destacar que nossos dados apontam para uma baixa presença de vínculos associativos entre as representantes do gênero feminino e organizações voltadas para a defesa desses mesmos grupos. Ainda que possamos considerar que a participação em organizações assistenciais esteja ligada, de alguma forma, à defesa de interesses daqueles grupos, é possível sugerir que nesse caso o perfil de atuação parlamentar das mulheres não tem relação direta com suas bases associativas.

Por outro lado, os dados mostram que para o caso das deputadas se reproduz o que outras pesquisas (Pinheiro, 2006; Marenco e Serna, 2007) já identificaram: entre os vínculos associativos mais presentes nas carreiras de parlamentares brasileiros, estão aqueles relacionados ao mundo do trabalho (sindicatos, organizações profissionais) e movimentos sociais (movimentos estudantis, organizações de mulheres, por exemplo). A participação nessas modalidades associativas constitui, assim, importante base social do recrutamento político no Brasil, tanto para homens como para mulheres.

Esses dados corroboram a literatura esboçada anteriormente que aponta diferenças significativas no campo associativo, bem como seus impactos demo- 
cráticos. Ao crescente processo de sindicalização feminina ${ }^{6}$ segue o aumento no número de mulheres que exercem o papel de lideranças sindicais, o que potencializa as possibilidades de ascensão política, na medida em que os sindicatos são espaços de participação que apresentam estruturas mais abrangentes e complexas, com diferentes frentes de atuação e de relações. Os sindicatos ${ }^{7}$ promovem o desenvolvimento de habilidades políticas, ampliando a base de conhecimentos e de relações políticas e sociais. No caso das deputadas, a atuação sindical segue um padrão de evolução para cargos superiores de liderança ${ }^{8}$, da mesma forma como ocorre em função de sua atuação em outros movimentos sociais, a exemplo do movimento estudantil e de mulheres ${ }^{9}$, a depender das respectivas configurações e contextos ${ }^{10}$. Como esboçado anteriormente, a atuação em movimentos sociais implica em participar em diferentes espaços e estabelecer articulações com outros grupos, indivíduos e instituições. Em muitas redes de movimentos sociais, a participação de sindicatos, partidos políticos e agentes governamentais é característica central. Assim, como veremos mais adiante, percebe-se, para o caso das deputadas, importantes correlações entre o engajamento sindical e em movimentos sociais, com destaque para o movimento estudantil.

\footnotetext{
6 Simões e Matos (2010) analisam o aumento da sindicalização feminina: "Dados apresentados por sindicatos de trabalhadores, compilados através da PNAD, revelam que, entre os anos de 1998 e 2006, enquanto a participação no mercado de trabalho para as mulheres aumentou em 37\% (comparando-se com 22\% para os homens), a participação no processo de sindicalização cresceu em $69 \%$ entre elas (comparando-se com um crescimento de 39\% entre os homens). As mulheres representam hoje 40\% das pessoas sindicalizadas no país (em 1998, eram 35\%). O crescimento nessa forma de participação feminina ocorreu em todos os setores da economia, inclusive entre os trabalhadores rurais. De acordo com o Departamento Feminino da Central Única dos Trabalhadores (a CUT), as trabalhadoras femininas estão se filiando aos sindicatos com o objetivo de lutar pela remuneração igual para o trabalho feminino, pelo combate ao assédio sexual e moral no trabalho e em busca de melhorias nas condições gerais de trabalho" (Folha de São Paulo, 8/10/08, p. 23).

Há, certamente, que se desagregar e diferenciar esse segmento, que apresenta diferentes configurações e relações. A CUT, por exemplo, aprovou uma medida de cotas para estimular o aumento de lideranças femininas nos sindicatos filiados.

8 Podemos exemplificar com o caso da deputada Erika Kokay (PT/DF), que foi Diretora de Cultura do Sindicato dos Bancários, Brasília, DF, de 1986-1989; Presidente do Sindicato dos Bancários, Brasília, DF, de 1992-1998; Secretária-Geral da Confederação Nacional dos Bancários, São Paulo, SP, de 19941996; Diretora da FENAE - Federação Nacional dos Funcionários da Caixa, Brasília, DF, de 1999-2000; e Presidente da CUT-DF, Brasília, DF, de 2000-2002.

9 Como casos exemplares: Luciana Santos (PCdoB/PE) foi Presidente do Diretório Acadêmico de Engenharia e Computação, UFPE, Recife, PE, em 1985; Dirigente do Diretório Central dos Estudantes, DCE; e Vice-Presidente Regional, UNE, PE, de 1989-1991. Luci Choinacki (PT/SC) foi Coordenadora do Movimento Estadual de Mulheres, SC, de 1984-1987; e Membro da Coordenação Estadual do Movimento das Mulheres Trabalhadoras Urbanas, Florianópolis, SC, 2007.

10 Voltado para a análise da participação feminina no movimento estudantil na Universidade do Espírito Santo, o trabalho de Souza (2011) mostrou que, diferentemente da atuação masculina, a participação das mulheres no movimento estudantil não logrou o mesmo êxito no tocante à ascensão para o poder político-institucional.
} 
No caso do engajamento em "organização de mulheres", o mesmo geralmente aparece acompanhado de outros engajamentos associativos. Por exemplo, a participação no setorial de mulheres de uma central sindical ou, o que foi muito frequente, a participação num grupo feminino no interior de um engajamento militante religioso. Assim, entre as deputadas que têm alguma "militância" vinculada a assuntos e questões femininas, essa é construída, quase sempre, na sua relação com outros vínculos associativos.

É importante destacar ainda que a Tabela 3 mostra, para o período considerado, um crescimento do associativismo religioso, bem como daquele relacionado a organizações de mulheres. Aqui podemos adiantar outra dimensão da análise fatorial apresentada na Tabela 4 a seguir, qual seja, a de que se encontram satisfatoriamente agrupadas as organizações religiosas e de mulheres, com cargas de 0,689 e 0,682, respectivamente. Isso indica uma relação entre essas modalidades, sendo que as deputadas envolvidas na primeira tendem a participar da segunda. Assim, podemos concluir que o que cresceu no período investigado foi o número de deputadas que combinam uma militância religiosa com uma militância voltada para questões femininas. Fundamental chamar a atenção para o crescimento desse tipo de perfil associativo entre as deputadas brasileiras porque ele pode indicar um movimento de fortalecimento das barreiras já existentes para a entrada de temas propriamente feministas no Congresso Nacional, como o aborto por exemplo.

Tabela 4 - Análise fatorial das modalidades de associativismo entre deputadas federais

\begin{tabular}{c|c|c|c}
\hline \multirow{2}{*}{ modalidades } & \multicolumn{3}{|c}{ componentes } \\
\cline { 2 - 4 } & 1 & 2 & 3 \\
\hline religiosa & -.123 & .258 & .698 \\
\hline comunitária & .840 & -.141 & .031 \\
\hline estudantil & .320 & .554 & -.385 \\
\hline sindicatos & .320 & .554 & -.385 \\
\hline profissional & -.203 & .386 & -.222 \\
\hline assistencial & -.107 & -.176 & -.328 \\
\hline orgonização de mulheres & .134 & -.170 & .682 \\
\hline direitos humanos & .845 & .107 & .100 \\
\hline defesa de grupos & -.126 & -.248 & -.128 \\
\hline fiscalização & -.116 & .357 & .104 \\
\hline
\end{tabular}

Notas: $\mathrm{KMO}=.48 / \mathrm{Sig}$. Teste de Bartletts $=0,000$.

$43,1 \%$ de variação explicada por 3 fatores

Foi considerado 0 agregado de respostas das deputadas das três legislaturas. 
Como já registramos, além da identificação dos níveis de associativismo entre as deputadas, também nos interessa verificar a existência de relações entre as distintas modalidades identificadas entre o grupo. Ou seja, existiria alguma tendência de variação conjunta entre as distintas formas de associativismo entre essas representantes? Para tanto, utilizamos a técnica de redução de dimensionalidade chamada de análise fatorial, útil quando se trata de identificar os inter-relacionamentos entre um grande número de variáveis e também para explicá-las em termos de dimensões latentes comuns (Hair, Anderson e Tatham, 1987). Como se trata de uma técnica de interdependência, a análise fatorial considera cada uma das medidas observadas (formas de associativismo) como dependentes em relação a um grupo de variáveis não observadas ou hipotéticas (fatores). Desta forma, tal procedimento nos indicará basicamente como os conjuntos de variáveis sobre associativismo se relacionam e se agrupam em dimensões ou fatores subjacentes. Para simplificar a análise, optamos aqui por utilizar apenas os dados agregados, sem divisão por legislatura. Sendo assim, é preciso considerar a repetição dos casos de reeleição.

Tendo em mente nossos objetivos e a natureza dos dados, empregamos a técnica de rotação ortogonal Varimax e limitamos os fatores a três. O resultado do teste de significância de Batletts e o valor do KMO de 0,48 (muito próximo dos 0,5 apontado pela literatura como valor crítico) revela a pertinência dessa redução de dimensionalidade.

Passando aos fatores, podemos identificar que o primeiro reúne as associações comunitárias e de direitos humanos, ambas com cargas fatoriais expressivas $(0,84)$. Esses dados revelam que, entre o grupo analisado, aquelas representantes envolvidas na primeira modalidade tendem também a se envolver com a segunda. Esse fator é o mais claramente distinto na análise, pois nenhuma outra forma de associativismo atingiu cargas fatoriais superiores a 0,3 na primeira coluna, indicando assim que essas duas modalidades se distinguem consideravelmente de todas as demais.

O segundo fator é bem menos preciso e reúne o maior número de modalidades com cargas fatoriais de distintas intensidades. As duas formas que mais carregam nesse componente são as organizações estudantis e sindicais (0,55 nos dois casos), mostrando clara associação entre as duas no grupo de representantes pesquisado. As associações profissionais e de fiscalização de governo alcançaram cargas fatoriais inferiores a 0,4 , patamar considerado 
mínimo para o agrupamento de variáveis em fatores. Ainda assim, essa foi a maior carga fatorial da variável, mostrando então que a mesma não se agrupa consideravelmente a nenhum dos fatores extraídos. O mesmo ocorre com as organizações de fiscalização, com carga de 0,357. Esse resultado indica a independência dessas modalidades em relação às demais. O mesmo pode ser dito sobre as organizações de defesa de grupos, que apesar do sinal negativo da carga fatorial alcança valor ainda menor $(0,248)$.

Por fim, no terceiro fator se encontram satisfatoriamente agrupadas, como já analisado anteriormente, as organizações religiosas e de mulheres, com cargas de 0,689 e 0,682, respectivamente. Isso indica uma relação entre essas modalidades e que deputadas envolvidas na primeira tendem a participar da segunda. As organizações assistenciais, assim como ocorreu com as modalidades mencionadas no parágrafo anterior, também revelaram independência, com carga fatorial negativa inferior a 0,4 . Este dado corrobora as análises que apontam as diferentes modalidades, práticas e impactos (positivos ou negativos) das associações para a democracia. De maneira geral, associações filantrópicas ou assistenciais estão voltadas para a prestação de serviços sociais e se envolvem menos em redes de articulação política, com maiores restrições em sua capacidade de representação dos seus públicos (Gurza Lavalle, Houtzager e Castello, 2006).

Instigados por esses quatro casos de relativa independência, rodamos uma nova análise fatorial ampliando o número de fatores para quatro. Nossa expectativa seria a de que essas variáveis pudessem se agrupar nesse componente adicional extraído, porém isso não ocorreu e as novas cargas fatoriais continuaram a indicar a não adequação aos fatores.

Em síntese, foi possível identificar três grupos fundamentais de ativismo em razão das variações conjuntas: o primeiro reunindo associações comunitárias e de direitos humanos; o segundo associando organizações sindicais e estudantis; e o terceiro agrupando organizações religiosas e de mulheres.

Nessa investigação, coletamos dados também sobre a participação das deputadas em Conselhos Gestores de Políticas Públicas. Trata-se de instâncias de controle e deliberação de políticas que apresentam um desenho institucional estruturado e sistêmico, organizado nas três esferas governamentais (município, estado e união). A característica que os distinguem no interior da rede estatal de produção e controle de políticas é a paridade na representação entre sociedade civil e Estado. Incluímos esse tipo de 
participação na nossa investigação porque várias pesquisas já detectaram a significativa presença feminina nessas instâncias quando comparadas às instâncias tradicionais de representação política. Nos Conselhos Gestores, a diferença entre homens e mulheres nas suas composições é bem menor daquela encontrada nos executivos e legislativos. Desse modo, os Conselhos Gestores se constituem em importantes portas de entrada para as mulheres no sistema político brasileiro. Considerando isso, é relevante conhecer o peso dessa participação na trajetória daquelas - poucas - que conseguem entrar no sistema político pelas vias tradicionais, ou seja, o processo eleitoral. A Tabela 5 apresenta a frequência de participação em conselhos encontrada entre as deputadas:

Tabela 5 - Participação em conselhos entre deputadas federais, por legislatura (\%)

\begin{tabular}{c|c|c|c|c}
\hline \multirow{2}{*}{} & \multicolumn{4}{|c}{ legislaturas } \\
\cline { 2 - 5 } & $2003-2007$ & $2007-2011$ & $2011-2015$ & agregado \\
\hline conselhos & 48,1 & 40,4 & 34 & 40,8 \\
\hline $\mathrm{n}$ & 52 & 52 & 53 & 157 \\
\hline
\end{tabular}

Fonte: Pesquisa Associativismo e representação política feminina.

Como podemos constatar, é bem significativa a presença dos Conselhos Gestores nas suas carreiras políticas. Esses dados nos levam a sugerir que esse tipo de participação não é apenas uma porta de entrada alternativa para as mulheres no sistema político, mas também uma marca importante da trajetória daquelas que entram nesse sistema pelas portas tradicionais. Esses dados parecem corroborar pesquisas anteriores (Borba e Ribeiro, 2010; Ribeiro e Borba, 2011) que mostram que, tanto no Brasil quanto na América Latina, não existe uma oposição entre as formas de engajamento relacionadas às instituições representativas e às ligadas ao associativismo e à participação mais direta. São, portanto, formas complementares e muitas vezes mobilizadas pelos mesmos atores sociais.

\section{Associativismo e pertencimento partidário}

A Tabela 6 apresenta o número de deputadas por partidos, nas 3 legislaturas. Lembramos que esses números não dizem respeito apenas aos mandatos ativos. 
Tabela 6 - Partidos das deputadas, por legislatura

\begin{tabular}{c|c|c|c|c|c|c|c|c}
\hline \multirow{2}{*}{ partido } & \multicolumn{7}{|c}{ legislaturas } \\
\cline { 2 - 9 } & \multicolumn{2}{|c|}{$2003-2007$} & \multicolumn{2}{c}{$2007-2011$} & \multicolumn{2}{c}{$2011-2015$} & \multicolumn{2}{c}{ agregado } \\
\cline { 2 - 9 } & $\mathrm{N}$ & $\%$ & $\mathrm{~N}$ & $\%$ & $\mathrm{~N}$ & $\%$ & $\mathrm{~N}$ & $\%$ \\
\hline PT & 15 & 28,8 & 11 & 21,2 & 11 & 20,8 & 37 & 23,6 \\
\hline PMDB & 9 & 17,3 & 9 & 17,3 & 9 & 17 & 27 & 17,2 \\
\hline PSB & 5 & 9,6 & 6 & 11,5 & 6 & 11,3 & 17 & 10,8 \\
\hline PCdoB & 5 & 9,6 & 5 & 9,6 & 6 & 11,3 & 16 & 10,2 \\
\hline PSDB & 5 & 9,6 & 4 & 7,7 & 3 & 5,7 & 12 & 7,6 \\
\hline PP & 1 & 1,9 & 3 & 5,8 & 4 & 7,5 & 8 & 5,1 \\
\hline PFL & 5 & 9,6 & 2 & 3,8 & 1 & 1,9 & 8 & 5,1 \\
\hline PR & - & - & 7 & 13,5 & - & - & 7 & 4,5 \\
\hline PTB & 3 & 5,8 & - & - & 2 & 3,8 & 5 & 3,2 \\
\hline PPS & 1 & 1,9 & 1 & 1,9 & 1 & 1,9 & 3 & 1,9 \\
\hline PDT & - & - & 1 & 1,9 & 2 & 3,8 & 3 & 1,9 \\
\hline PSOL & 2 & 3,8 & 1 & 1,9 & - & - & 3 & 1,9 \\
\hline PL & 1 & 1,9 & 1 & 1,9 & 1 & 1,9 & 3 & 1,9 \\
\hline PSC & - & - & - & - & 2 & 3,8 & 2 & 1,3 \\
\hline DEM & - & - & 1 & 1,9 & 1 & 1,9 & 2 & 1,3 \\
\hline PMN & - & - & - & - & 1 & 1,9 & 1 & 0,6 \\
\hline PSD & - & - & - & - & 1 & 1,9 & 1 & 0,6 \\
\hline PTdoB & - & - & - & - & 1 & 1,9 & 1 & 0,6 \\
\hline PV & - & - & - & - & 1 & 1,9 & 1 & 0,6 \\
\hline & 52 & 100 & 52 & 100 & 53 & 100 & 157 & 100 \\
\hline
\end{tabular}

Fonte: Pesquisa Associativismo e representação política feminina.

No que se refere ao pertencimento partidário das deputadas, vale sublinhar que o período investigado não alterou substantivamente aquilo que Pinheiro (2006) detectou para períodos anteriores: partidos considerados de centro e esquerda tendem a eleger mais mulheres, como é o caso daqueles que estão no topo da Tabela 6. Para identificar possíveis relações entre a legenda partidária das deputadas e o seu nível de associativismo, abaixo (Tabela 7) apresentamos os cruzamentos e testes de associação do índice somatório de ativismo com os cinco partidos que contam com maior presença feminina (PT, PMDB, PSDB, PCdoB e PSB). ${ }^{11}$

${ }^{11}$ Como trabalhamos aqui com a totalidade das deputadas das três legislaturas não há necessidade de considerarmos os níveis de significância dos testes de associação, que se referem à probabilidade de 
Tabela 7 - Índice de associativismo por partido

\begin{tabular}{|c|c|c|c|c|c|c|c|}
\hline \multirow{2}{*}{ partido } & \multirow[t]{2}{*}{ legislatura } & \multicolumn{5}{|c|}{ índice de associativismo } & \multirow[t]{2}{*}{ gamma } \\
\hline & & 0 & 1 & 2 & 3 & 4 & \\
\hline \multirow[t]{4}{*}{ PT } & $2003-2007$ & 6,7 & 46,7 & 33,3 & 6,7 & 6,7 & 45 \\
\hline & $2007-2011$ & 9,1 & 36,4 & 36,4 & 18,2 & 0 & 56 \\
\hline & $2011-2015$ & 18,2 & 45,5 & 27,3 & 0 & 9,1 & 42 \\
\hline & agregado & 10,8 & 43,2 & 32,4 & 8,1 & 5,4 & 48 \\
\hline \multirow[t]{4}{*}{ PMDB } & $2003-2007$ & 55,6 & 33,3 & 0 & 11,1 & 0 &,- 5 \\
\hline & $2007-2011$ & 55,6 & 22,2 & 11,1 & 11,1 & 0 &,- 29 \\
\hline & 2011-2015 & 55,6 & 11,1 & 22,2 & 11,1 & 0 &,- 09 \\
\hline & agregado & 55,6 & 22,2 & 11,1 & 11,1 & 0 &,- 3 \\
\hline \multirow[t]{4}{*}{ PSDB } & $2003-2007$ & 60 & 40 & 0 & 0 & 0 &,- 67 \\
\hline & $2007-2011$ & 75 & 25 & 0 & 0 & 0 &,- 77 \\
\hline & $2011-2015$ & 55,6 & 11,1 & 0 & 0 & 0 &,- 13 \\
\hline & agregado & 58,3 & 41,7 & 0 & 0 & 0 &,- 57 \\
\hline \multirow[t]{4}{*}{$\mathrm{PCd} 0 \mathrm{~B}$} & $2003-2007$ & 0 & 0 & 20 & 60 & 20 & 94 \\
\hline & $2007-2011$ & 0 & 40 & 20 & 40 & 0 & 69 \\
\hline & $2011-2015$ & 0 & 50 & 16,7 & 33,3 & 0 & , 7 \\
\hline & agregado & 0 & 31,3 & 18,8 & 43,8 & 6,3 & ,77 \\
\hline \multirow[t]{4}{*}{ PSB } & 2003-2007 & 20 & 60 & 20 & 0 & 0 &,- 07 \\
\hline & $2007-2011$ & 33,3 & 50 & 16,7 & 0 & 0 &,- 16 \\
\hline & $2011-2015$ & 33,3 & 52,9 & 16,7 & 0 & 0 &,- 00 \\
\hline & agregado & 29,4 & 52,9 & 16,7 & 0 & 0 &,- 08 \\
\hline
\end{tabular}

Fonte: Pesquisa Associativismo e representação política feminina.

No caso do PT verificamos nas três legislaturas uma concentração das deputadas nos pontos 1 e 2 da escala. Ao somarmos o percentual daquelas que participam de 1 e 2 modalidades chegamos a $80 \%$ na primeira legislatura, $72,8 \%$ na segunda e terceira. Em termos de associação, podemos afirmar que o atributo "pertencer" ao Partido dos Trabalhadores está relacionado positivamente (de forma moderada) ao associativismo das representantes, ou seja, entre as petistas podemos identificar uma tendência maior de envolvimento. A pesquisa de Coradini (2007) sobre políticos eleitos entre 1994 e 2003 também apontou o PT como um dos partidos que mais aglutina vínculos associativos. Para o autor, o próprio aumento da ocorrência de 
vínculos associativos entre políticos detectado no período está relacionado à expansão do PT.

Situação bastante distinta pode ser encontrada no caso do PMDB, pois encontramos em todas as legislaturas a maioria de suas deputadas $(55,6 \%)$ no ponto inferior extremo do índice, equivalente a nenhum envolvimento associativo. As associações refletem esse quadro com sinais negativos, confirmando que o pertencimento a essa legenda está negativamente relacionado ao associativismo.

Essa situação se repete entre a deputadas do PSB, com uma inversão dos percentuais entre os pontos 0 e 1 e ocorrências no ponto 2 do índice. Essas diferenças fazem com que as associações negativas tenham intensidades bem menores, quase inexpressivas. Em termos comparativos, poderíamos dizer que as deputadas do PSB têm uma participação associativa maior do que as do PMDB.

A mesma relação, porém mais intensa, pode ser encontrada entre as representantes do PSDB, sobretudo nas duas primeiras legislaturas. Nesse caso, temos $60 \%$ e $75 \%$ das deputadas sem qualquer envolvimento nas modalidades que compõem o índice. Consistentemente, as associações são todas negativas e fortes, ainda que verifiquemos uma redução nessa intensidade na última legislatura.

Por fim, destacamos a situação favorável do PCdoB, que concentra suas representantes nos pontos superiores do índice. Todas as deputadas desse partido apresentaram algum envolvimento associativo e a maioria (80\% na primeira legislatura) participa de 3 ou 4 modalidades. Na segunda e terceira legislatura ocorre uma queda nesse associativismo, porém os níveis continuam comparativamente elevados. ${ }^{12}$

Em síntese, esses dados parecem apontar para um cenário de relevância dos partidos no que diz respeito ao associativismo. Deputadas de distintas agremiações parecem possuir distintos perfis associativos, alguns mais intensos e outros mais frágeis. Para aprofundar esse tipo de análise realizamos procedimento semelhante, porém tomando para os cruzamentos cada modalidade de forma isolada (Tabela 8). ${ }^{13}$

\footnotetext{
12 A comparação deve ser cuidadosa nesses casos, pois assim como o PSB, o PCdoB conta com apenas cinco deputadas, enquanto o PT conta com 15.

13 Foram incluídas nessa etapa apenas as seis modalidades com maior ocorrência entre as deputadas.
} 
Tabela 8 - Modalidades de associativismo por Partido (\%)

\begin{tabular}{|c|c|c|c|c|c|c|c|c|c|c|c|c|c|}
\hline \multirow{3}{*}{ partido } & \multicolumn{13}{|c|}{ modalidade } \\
\hline & & \multicolumn{2}{|c|}{ sindicatos } & \multicolumn{2}{|c|}{ profissionais } & \multicolumn{2}{|c|}{ mulheres } & \multicolumn{2}{|c|}{ estudantil } & \multicolumn{2}{|c|}{ comunitária } & \multicolumn{2}{|c|}{$\begin{array}{c}\text { direitos } \\
\text { humanos }\end{array}$} \\
\hline & & $\%$ & $y$ & $\%$ & y & $\%$ & $y$ & $\%$ & $y$ & $\%$ & $y$ & $\%$ & $y$ \\
\hline \multirow{4}{*}{ PT } & $2003-2007$ & 60 & 60 & 40 & 48 & 13,3 &,- 01 & 6,7 &,- 46 & 13,3 & 27 & 20 & ,48 \\
\hline & $2007-2011$ & 81,8 & 90 & 9,1 &,- 04 & 9,1 &,- 26 & 18,2 & ,13 & 18,2 & ,34 & 27,3 & ,76 \\
\hline & 2011-2015 & 54,5 & ,76 & 9,1 &, 33 & 18,2 &,- 05 & 9,1 &,- 03 & 18,2 &, 49 & 18,2 & ,47 \\
\hline & agregado & 64,9 & ,76 & 21,6 &, 39 & 13,5 &,- 06 & 10,8 &,- 12 & 16,2 &, 36 & 21,6 &, 59 \\
\hline \multirow{4}{*}{ PMDB } & 2003-2007 & 0 & - & 11,1 &,- 51 & 22,2 & ,37 & 0 & - & 11,1 & 1 & 11,1 &,- 03 \\
\hline & $2007-2011$ & 0 & - & 0 & - & 22,2 & ,37 & 11,1 &,- 22 & 11,1 &,- 03 & 11,1 & 1 \\
\hline & $2011-2015$ & 0 & - & 0 & - & 22,2 & ,20 & 11,1 & ,11 & 11,1 & ,11 & 11,1 & 11 \\
\hline & agregado & 0 & - & 3,7 &,- 65 & 22,2 & ,31 & 7,4 &,- 33 & 11,1 &, 06 & 11,1 &, 06 \\
\hline \multirow{4}{*}{ PSDB } & 2003-2007 & 0 & - & 40 & ,37 & 0 & - & 0 & - & 0 & - & 0 & - \\
\hline & 2007-2011 & 0 & - & 0 & - & 0 & - & 0 & - & 0 & - & 0 & - \\
\hline & 2011-2015 & 0 & - & 0 & - & 0 & - & 0 & - & 0 & - & 0 & - \\
\hline & agregado & 0 & - & 16,7 & ,14 & 0 & - & 0 & - & 0 & - & 0 & - \\
\hline \multirow{4}{*}{ PCdoB } & 2003-2007 & 100 & - & 40 & ,73 & 40 & ,70 & 60 & 88 & 20 & ,46 & 40 & ,75 \\
\hline & 2007-2011 & 60 &, 56 & 20 &, 46 & 20 & , 26 & 60 & 85 & 20 &, 35 & 20 & ,46 \\
\hline & 2011-2015 & 50 & ,61 & 16,7 & ,64 & 33,3 & 48 & 50 & 91 & 16,7 & ,36 & 16,7 &, 36 \\
\hline & agregado & 68,8 & ,72 & 25 &, 42 & 31,3 &, 51 & 56,3 & 88 & 18,8 & ,39 & 25 & ,56 \\
\hline \multirow{4}{*}{ PSB } & $2003-2007$ & 40 & ,17 & 20 &,- 16 & 0 & - & 20 & ,26 & 20 & ,46 & 0 & - \\
\hline & 2007-2011 & 33,3 &, 03 & 16,7 &, 35 & 0 & - & 16,7 &, 05 & 16,7 & ,24 & 0 & - \\
\hline & $2011-2015$ & 33,3 &, 59 & 16,7 & 64 & 0 & - & 0 & - & 16,7 &, 36 & 16,7 & 36 \\
\hline & agregado & 35,3 & ,12 & 17,6 & , 18 & 0 & - & 11,8 &,- 05 & 16,7 &, 35 & 5,9 &,- 31 \\
\hline
\end{tabular}

Fonte: Pesquisa Associativismo e representação política feminina.

Notas: 0 s percentuais se referem às deputadas que pertencem ao partido e que participam das modalidades.

Considerando o PT, o envolvimento mais intenso se dá de forma inequívoca com as organizações sindicais. A maioria das deputadas desse partido participa dessa modalidade de associativismo, considerando as três legislaturas. Há certa oscilação nos percentuais, partindo de 60\% em 2003-2007, chegando a 81,8\% em 2007-2011 e caindo para 54,5\% na atual legislatura. Os coeficientes de associação são todos compatíveis com esses números, chegando a 0,90 na segunda legislatura. A segunda modalidade com maior envolvimento de deputadas petistas são as organizações profissionais, que atingem expressivos 40 pontos percentuais na primeira legislatura, porém sofrem queda expressiva nas demais (9,1\% em 2007-2011 e 2011-2015). As 
associações acompanham essa variação. As organizações ligadas à defesa dos direitos humanos aparecem na terceira posição, todavia com patamares bem inferiores e grande oscilação. Depois de sofrer elevação de mais de 7 pontos percentuais entre as duas primeiras legislaturas (partindo de 20 para 27,3), na composição atual da Câmara verificamos uma queda significativa para $18,2 \%$. O coeficiente de associação positivo atinge 0,76 na segunda legislatura, revelando forte relacionamento.

O envolvimento com as organizações de mulheres é pequeno (de 9,1 a 13,3 pontos percentuais) e se mantém relativamente estável entre as legislaturas. Também é reduzida a presença nas organizações estudantis, apesar dos 18,2\% alcançados na segunda legislatura. As organizações comunitárias contam com envolvimento ligeiramente maior, mantendo-se estável na casa dos $18 \%$ nas duas últimas legislaturas.

Passando ao PMDB, verificamos a inexistência de qualquer envolvimento com os sindicatos e baixa presença em todas as demais modalidades, com exceção das organizações de mulheres. Apenas nessa modalidade os percentuais atingem 22 pontos e as associações de todas as legislaturas deixam de ser negativas, ainda que permaneçam fracas. Ressalte-se que há uma importante história de organização feminina no interior do PMDB, o que pode ajudar a explicar a associação encontrada.

O caso do PSDB é ainda mais nítido, pois verificamos envolvimento apenas nas organizações profissionais. O envolvimento nessa modalidade registra $40 \%$ na primeira legislatura, mas cai a 0 nas duas posteriores. Trata-se, portanto, do partido com o menor nível de associativismo dentre os analisados aqui. Cabe mencionar que na coleta de dados foi possível perceber que as carreiras políticas das deputadas do PSDB estão bastante marcadas por destacadas carreiras profissionais. É compreensível, assim, o conjunto de dados que apontam para uma associação entre essas deputadas e as organizações profissionais.

O PCdoB, como apontamos anteriormente, concentra deputadas com perfil associativo intenso, com várias participações. Hierarquizando os níveis de envolvimento pelos percentuais agregados teríamos os sindicatos na primeira posição, porém com uma forte tendência de queda. Em 2003-2007, todas as deputadas desse partido participavam de sindicatos, caindo para $60 \%$ na legislatura seguinte e para 50\% na atual. As organizações estudantis aparecem na segunda posição com maior estabilidade, pois registram $60 \%$ 
de envolvimento nas duas primeiras legislaturas e uma queda de 10 pontos na terceira. Os coeficientes de associação se mantêm estavelmente positivos e fortes. As organizações de mulheres aparecem, na sequência, com $40 \%$ na primeira legislatura, queda acentuada para $20 \%$ na segunda e recuperação de 13 pontos na atual. As associações refletem essa queda, indo de 0,26 nesse momento de queda a 0,70 na legislatura que vai de 2003 a 2007. As organizações profissionais e de direitos humanos apresentam resultados semelhantes, começando com consideráveis $40 \%$ na primeira legislatura e caindo para 20 e 16 pontos nas duas seguintes. Por fim, as associações comunitárias são as que menos contam com o envolvimento das deputadas desse partido. Em 2003-2007 e 2007-2011 eram 20\% as participantes e na legislatura atual 16,7\%.

O PSB conta com deputadas com perfil fracamente associativo, porém é possível verificar a ocorrência de envolvimento em distintas modalidades. Os sindicatos novamente aparecem como a forma mais recorrente, atingindo $40 \%$ na primeira legislatura e caindo para $33 \%$ nos dois períodos posteriores. A segunda modalidade entre essas deputadas são as organizações profissionais que contam com o envolvimento de $20 \%$ entre 2003 e 2007. Com trajetória semelhante à identificada no caso dos sindicatos, aqui também ocorre queda para 16,7 nos dois momentos seguintes. O mesmo ocorre com as associações comunitárias. Queda ainda mais forte se verifica no caso das entidades estudantis, que atingem 0 na atual legislatura depois de contarem com $20 \%$ de envolvimento na primeira. Por fim, as organizações de direitos humanos registram envolvimento mínimo apenas na última legislatura e as entidades de mulheres não contam com qualquer envolvimento ao longo do tempo coberto por essa pesquisa. Em termos gerais, pode-se afirmar que entre as deputadas desse último partido a intensidade do associativismo tem sido reduzida ao longo do período analisado.

De maneira geral, esses dados confirmam algumas análises que avaliam correlações positivas entre partidos e práticas associativas. Por um lado, confirmam a relação positiva, quantitativamente falando, entre tipo de partido e atuação associativa. Estudos de Coradini (2007) e de Marenco e Serra (2007), por exemplo, atestam que, independentemente de gênero, os políticos vinculados aos partidos de direita, a exemplo do PFL e do PP, apresentam fraco vínculo associativo, diferente dos partidos de esquerda que "recrutam suas bancadas predominantemente no setor público, na classe média assalariada, entre sindicalistas, lideranças associativas e lideranças de movimentos 
sociais" (Marenco e Serra, 2007, p. 93), com destaque para o PT, "um dos principais aglutinadores, em termos partidários, dos portadores desse tipo de recurso" (Coradini, 2007, p. 183).

Por outro lado, há uma importante correlação entre o perfil político-partidário e o tipo de vinculação associativa. Assim, não é difícil entender a forte concentração de deputadas de partidos de esquerda vinculadas a sindicatos e determinados tipos de movimentos sociais, haja vista as intrínsecas relações entre estas práticas associativas e a trajetória da constituição desses partidos. Seguindo esse padrão, da mesma forma como há uma importante base de atuação sindical em deputadas do PT e do PCdoB, por exemplo, encontramos uma significativa base de atuação de deputadas do PMDB junto a organizações de mulheres, condizente com uma trajetória feminina atuante no interior deste partido.

\section{Considerações finais}

Embora reconheça a interferência - e as inter-relações - de outras variáveis que são constitutivas de trajetórias de sucesso eleitoral, nosso trabalho confirma, fazendo uso de dados biográficos das deputadas brasileiras, a validade de perspectivas teóricas que problematizam análises que generalizam, para o campo associativo, os seus impactos democráticos na promoção do desenvolvimento individual, social e político-institucional.

Baseados na ideia de "ecologia democrática das associações", verificamos consistência na tese que decompõe as características das associações e seus diferentes - e em muitos casos - contraditórios benefícios democráticos. Assim, faz diferença, para a trajetória política, o tipo de vinculação associativa. A atuação em grupos mais periféricos, como grupos religiosos e associações comunitárias, pode ser boa para o desenvolvimento de solidariedades e de lideranças locais, por exemplo, mas são menos eficazes na capacidade de inserção em redes sociais e político institucionais. De outra forma, a atuação em sindicatos e em movimentos sociais potencializa o desenvolvimento de habilidades políticas com avaliação de estratégias, enfrentamentos de conflitos e articulação e negociações com diferentes atores político-institucionais, inserindo grupos e indivíduos em redes mais densas de articulação que ampliam a possibilidade de apoios e de reconhecimento social, importantes recursos nos processos eleitorais. Assim, os nossos dados confirmam que a diferença verificada, na população em geral, no perfil da atuação associativa 
entre homens e mulheres, pode ser, como analisou Sacchet (2009), uma chave importante para a compreensão do baixo índice de inclusão política eleitoral das mulheres. Como vimos, a vinculação das mulheres, no plano da população em geral, é mais frequente com grupos locais, assistenciais e religiosos, que são menos capazes de fornecer os recursos exigidos pelos processos de recrutamento político. A baixa presença de deputadas com atuação em associações mais locais e periféricas, se comparadas com as que têm atuado em sindicatos, associações profissionais e movimentos sociais, corrobora esta análise.

Outra importante dimensão do fenômeno da relação entre associação e representação eleitoral diz respeito ao pertecimento partidário. De fato, confirma-se aqui o resultado de outros estudos que apontam diferenças no perfil participativo de nossos parlamentares, com claras distinções quantitativas e qualitativas - dadas pelas respectivas trajetórias e projetos político-ideológicos.

Para concluir, cumpre notar que nossos dados mostraram a pertinência de uma exploração mais profunda das relações entre as distintas modalidades de participação associativa, o que pode indicar não apenas o fenômeno da multimilitância nesse universo, como também, e sobretudo, revelar seus impactos na atuação parlamentar, como foi sugerido para o caso da associação encontrada entre a participação em organizações religiosas e de mulheres, em crescimento no período investigado.

\section{Referências bibliográficas}

ABERS, Rebecca \& BÜLOW, Marisa von. 2011. "Movimentos sociais na teoria e na prática: como estudar o ativismo através da fronteira entre Estado e sociedade?”. Sociologias, n. 28, p. 52-84.

ARAÚJO, Clara. 2010. "Rotas de ingresso, trajetórias e acesso de mulheres ao legislativo: um estudo comparado entre Brasil e Argentina”. Revista Estudos Feministas, v. 18, n. 2, p. 567-584.

BAGGETTA, Matthew. 2009. "Civic opportunities in associations: interpersonal interaction, governance experience and institutional relationships". Social Forces, v. 88, n. 1, p. 175-199.

BORBA, Julian \& RIBEIRO, Ednaldo A. 2010. "Participação convencional e não convencional na América Latina”. Revista Latino-Americana de Opinión Pública, v. 1, p. 53-76. 
CAIAZZA, Amy \& PUTNAM, Robert. 2005. "Women's status and social capital in the United States". Journal of Women, Politics, and Policy, v. 27, n. 1-2, p. 69-84.

CARROLL, Susan J. \& FOX, Richard L. 2006. "Introduction: gender and electoral politics into the twenty-first century". In: CARROLL, Susan J. \& FOX, Richard L. (eds.). Gender and elections. New York: Cambridge University Press.

CHAMBERS, Simone \& KOPSTEIN, Jeffrey. 2006. "Civil society and the state". In: DRYZEK, John; HONIG, Bonnie \& PHILLIPS, Anne (eds.). The Oxford handbook of political theory. Oxford: Oxford University Press.

CORADINI, Odaci L. 2007. "Engajamento associativo-sindical e recrutamento de elites políticas: tendências recentes no Brasil”. Revista de Sociologia e Política, v. 28, p. 181-203.

DAGNINO, Evelina; OLVERA, Alberto J. \& PANFICHI, Aldo. 2006. “Para uma outra leitura da disputa pela construção democrática na América Latina”. In: DAGNINO, Evelina; OLVERA, Alberto J. \& PANFICHI, Aldo (orgs.). A disputa pela construção democrática na América Latina. São Paulo: Paz e Terra; Campinas: Editora da Unicamp.

DIANI, Mario \& BISON, Ivano. 2010. "Organizações, coalizões e movimentos”. Revista Brasileira de Ciência Política, n. 3, p. 220-249.

FUNG, Archon. 2003. "Associations and democracy: between theories, hopes, and realities". Annual Review of Sociology, v. 29, p. 515-539.

GOLDSTONE, Jack. 2003. "Bridging institutionalized and noninstitutionalized politics”. In: GOLDSTONE, Jack (ed). States, parties and social movements. Cambridge: Cambridge University Press.

GURZA LAVALLE, Adrián; HOUTZAGER, Peter \& CASTELLO, Graziela. 2006. "Representação política e organizações civis: novas instâncias de mediação e os desafios da legitimidade". Revista Brasileira de Ciências Sociais, n. 60, p. 43-66.

HAIR, Joseph; ANDERSON, Rolph E. \& TATHAM, Ronald L. 1987. Multivariate data analysis. New Jersey: Prentice-Hall.

LÜCHMANN, Lígia H. H. 2011. “Abordagens teóricas sobre o associativismo e seus efeitos democráticos". Trabalho apresentado no XV Congresso Brasileiro de Sociologia, Curitiba, julho.

\& ALMEIDA, Carla Cecília R. A. 2010. "Representação política 
das mulheres nos conselhos gestores de políticas públicas”. Katálysis, v.13, n.1, p. 86-94.

MARENCO, André \& SERNA, Miguel. 2007. "Por que carreiras políticas na esquerda e na direita não são iguais? recrutamento político em Brasil, Chile e Uruguai”. Revista Brasileira de Ciências Sociais, v. 22 n. 64, p. 93-113.

MELUCCI, Alberto. 2001. A invenção do presente: movimentos sociais nas sociedades complexas. Petrópolis: Vozes.

PATEMAN, Carole. 1992. Participação e teoria democrática. Rio de Janeiro: Paz e Terra.

PAXTON, Pamela. 2002. "Social capital and democracy: an interdependent relationship". American Sociological Review, v. 67, n. 2, p. 254-77.

PINHEIRO, Luana S. 2006. Vozes femininas na política: uma análise sobre mulheres parlamentares no pós-Constituinte. Dissertação de Mestrado. Brasília: Instituto de Ciências Sociais, Departamento de Sociologia, UnB. PUTNAM, Robert. 1995. "Bowling alone: America's declining social capital". Journal of Democracy, v. 6, n. 1, p. 65-78.

1996. Comunidade e democracia: a experiência da Itália moderna. Rio de Janeiro: FGV.

RIBEIRO, Ednaldo A. \&BORBA, Julian. 2011. "Participación y democracia en América Latina: los determinantes individuales de la participación política”. Foro Internacional, v. 204, p. 34-67.

ROBTEUTSCHER, Sigrid. 2005. Democracy and the role of associations. London, New York: Routledge.

SACCHET, Teresa. 2009. "Capital social, gênero e representação política no Brasil”. Opinião Pública, v. 15, n. 2, p.306-332.

SCHERER-WARREN, Ilse. 2006. "Das mobilizações às redes de movimentos sociais". Sociedade e Estado, v. 21, n.1, p. 109-130.

SCHWINDT-BAYER, Leslie A. 2010. Political power and women's representation in Latin America. New York: Oxford University Press.

SIMÕES, Solange \& MATOS, Marlise. 2010. "Ideias modernas e comportamentos tradicionais: a persistência das desigualdades de gênero no Brasil”. In: SOUZA, Márcio F. (org.). Desigualdades de gênero no Brasil: novas ideias e práticas antigas. Belo Horizonte: Argvmentvm.

SOUZA, Dayane S. 2011. Movimento estudantil na UFES e redemocratização: 
um estudo das trajetórias de mulheres. Monografia de conclusão de curso. Vitória: Departamento de Ciências Sociais, UFES.

STOLLE, Dietlind \& ROCHON, Thomas R. 1998. "Are all associations alike? member diversity, associational type, and the creation of social capital". American Behavioral Scientist, v. 42, n. 1, p. 47-65.

WARREN, Mark. 2001. Democracy and association. Princeton: Princeton University.

\section{Resumo}

Considerando as relações entre associativismo e democracia, neste trabalho analisamos o perfil associativo e participativo de deputadas federais brasileiras eleitas nas três últimas legislaturas. Os dados que o embasam foram coletados no perfil biográfico das deputadas disponível no portal da Câmara dos Deputados e nos seus sites pessoais. Encontramos uma significativa presença de vínculos associativos nas carreiras das deputadas, com concentração em determinadas modalidades associativas. Nossos dados sugerem também afinidades entre determinados vínculos associativos e pertencimento partidário e, no seu conjunto, mostram que a análise das relações entre associativismo e representação política fornece importantes chaves para a compreensão dos processos que envolvem a inclusão política de mulheres.

Palavras-chave: associativismo; representação política; gênero; democracia.

\section{Abstract}

Taking into account the relations between associativism and democracy, this paper analyzes the associative and participatory profiles of Brazilian congresswomen elected for the last three terms. Data were taken from the profile of these congresswomen that is available on the internet portal of the Chamber of Deputies and on their personal websites. A significant number of associative bonds were found throughout these women's careers, focusing on certain associative modalities. Our data also pointed to affinities between certain associative bonds and party affiliation, leading to the conclusion that the study of the relations between associativism and political representation provides important clues to the processes surrounding political inclusion of women.

Key words: associativism; political representation; gender; democracy.

Recebido em 31 de janeiro de 2012.

Aprovado em 30 de março de 2012. 